\title{
APPLICATION OF ELECTRIC FURNACE METHODS TO INDUSTRIAL PROCESSES.
}

Mr. H. Etchells, B.Met., M.Inst.Met., contributed the first paper to the symposium, entitled "Application of Electric Furnace Methods to Industrial Processes."

The development of electrochemicai and metallurgical processes has become, during the period of the war, not only a national necessity from a defensive standpoint but also from the standpoint of national economy, enabling us to produce many things :which formerly we bought from abroad, and also to augment our national resources by the utilization of materials formerly regarded as inferior and of little value.

Although the electrolytic methods of producing aluminium, soda, zinc, tin and lead from fused electrolytes may be regarded as furnace processes, they are not carried out at temperatures which produce real furnace problems, and I propose to exclude them from this review.

The study of the electric furnace is interesting because of its complexity. We attempt to convert electric energy into heat in a variety of ways, and have to use the physicochemical characteristics of the process in hand to the best advantage in order to accomplish good furnacemanship.

The standard writer usually tells us that there are three types of furnace :-

(I) Induction.

(2) Resistance.

(3) Arc.

In my opinion only the latter two headings count. The induction furnace was an attempt to heat on resistance principles, and I think most engineers agree that, although scientifically interesting, the induction furnace has failed to show a superiority over other electric furnace methods or to establish a monopoly in any particular industry. The latest addition to this type of furnace, however, is interesting because of its complete novelty. I refer to the Northrup high-frequency furnace, by which a graphite crucible is placed in the centre of the inductive field of a surrounding solenoid, through which high-frequency alternating currents are passed. Induction currents set up in the crucible and the metallic charge raise its temperature.

Resistance furnaces offer a very large field. One of the successful pioneers of this type of furnace is Mr. T. F. Baily, of Cleveland, Ohio, After ten or twelve years' experimenting he can to-day look round on a number of his furnaces installed in the States and doing satisfactory work in reheating steel, German silver and other metals for annealing, 


\section{APPLICATION OF ELECTRIC FURNACE METHODS}

These furnaces are constructed in units up to $900 \mathrm{kw}$. The principle of the Baily furnace is to employ a resistor material like broken electrode carbon, granulated coke, etc., which is disposed evenly in an open trough encircling the interior hearth of the furnace. Current is fed into this resistor by graphite electrodes which penetrate the furnace walls. The trough, of course, must be levelled up, as the carbon oxidizes from the surface.

As far as I am able to gather, the chief difficulties met with have been in the choice of a material for building the trough walls, which tend to fuse and run, especially if the resistor accumulates a large quantity of fusible ash residue. Carborundum appears to offer the best protection, but as it is also very conductive at high temperatures, it seems to me that the range of this method of construction is limited. This type of furnace has been particularly applied recently to the melting of brass, gun-metal and low temperature non-ferrous alloys, on which it has proved very successful. The power consumption is stated to be $400 \mathrm{kw}$. hours per ton for yellow brass on a twenty-four hour day.

The employment of a resistor solely as a heating unit for furnace temperatures over $\mathrm{x}, 100^{\circ} \mathrm{C}$. does not appear to have been practically realized yet, although a number of investigators are at work on the problem. I note that we are to have a contribution especially on this subject to-night, to which I look forward with considerable interest.

Resistance furnaces should be encouraged. They provide a much more satisfactory load from the central station viewpoint. The load differs from the arc furnace load in being exactly regulatable, and the furnaces are not subjected to the numerous shut-downs which afflict the arc furnace. The load factor can be kept up, 80 per cent. being a reasonable minimum figure to allow, while the maximum demand should never be more than ro per cent. above full load.

Among furnaces of the resistance class we may just mention graphitizing and carborundum furnaces. These products have for many years been exclusively American, but Great Britain, Norway and France are entering into competition. We may also reasonably assume that Germany has not denied herself of these products for want of means to manufacture.

There are furnaces which verge on the border-line between resistance and arc type. Almost all smelting furnaces come into this class. Electric smelting furnaces for copper oxide ores and residues are obtaining a big development in the States. Experiments in electric iron smelting have been going on since Heroult tackled the problem in Canada in 1907. As far as the industrial success in this field is concerned, the Swedish "Elektrometall" furnace seems to have been a success. Several furnaces similar to the arc furnace illustrated are now in successful operation in Sweden, absorbing up to 7,000 h.p. each. The charge itselt acts as a resistor, and regulation is obtained by varying the voltage. In constant-voltage furnaces, regulation is made by raising or lowering the electrode, which may at times form an arc in the circuit.

The electric smelting furnace is fairly localized to those districts where electric power is very cheap and charcoal plentiful. The power consumption per ton of pig iron in the "Elektrometall" furnace is given as $2,225 \mathrm{kw}$. hours and charcoal 0.40 tons per ton.

There is large scope for an electric smelting furnace which will reduce iron sands and finely divided ores, and which will utilize carbon as the reducing agent in other forms than charcoal. There are large 
deposits of iron ores in districts where water power is plentifal but fuel is very scarce, and the rate at which the nations of the world are using up their lump ore and coal supplies will eventually force them to use up these outlying deposits.

Ferro alloys and calcium carbide are generally made in furnaces which comprise a rammed carbon bottom, often water-cooled, with thin walls built up of refractive substances sometimes constituted from the actual raw material to be charged into the furnace or else of magnesite. The charge is fed in round the electrodes and the current maintains an arc at the tip of the suspended electrodes as well as leaking away through the charge. The charge is sometimes tapped and sometimes allowed to solidify.

The refining of ferro alloys is carried out in furnaces of the steel melting type, in which they are treated with oxidizing slags to remove the excess of carbon from the alloy which is gained in the smelting process. A few alloys with very high melting-point must be treated and allowed to solidify in fixed furnaces, from which they are chipped out.

Products such as calcium carbide and ferro alloys absorb relatively large quantities of electrical energy, 7,000 kw. hours per ton being the figure given for 5 per cent. $\mathrm{C}$ ferro-chrome alone. It is not surprising, therefore, to find that these industries are carried on in regions like the French Alps, Norway and certain parts of North America, where hydroelectric power is cheap. It is significant that a country like Norway, which has always been considered relatively a poor country industrially, should be coming so rapidly to the front in electrochemistry. Norway is gradually becoming one of the chief producers in artificial nitrates and perchlorates, in addition to the important position she holds in regard to ferro alloys. One wonders if something could not be done in certain parts of Wales, Ireland and the North of Scotland to attract these industries to Great Britain.

The greatest development in electric furnaces had taken place in the steel-making industry. It is now realized that electric furnaces have a definite rôle to fulfil in steel-making, and that the peculiar qualities of this steel render it especially suitable for certain work irrespective of the question of price.

On the screen you will see a group of small and to some extent intricate steel castings. Many of these gear-wheels only need touching up with a file to make them quite usable. Basic electric cast steel can be made of carbon, 0.25 per cent.; manganese, 0.35 per cent. ; sulphur and phosphorus, under 0.02 per cent.; and such a steel will give 34 tons tensile, 30 per cent. elongation and 40 per cent. reduction of area. Such a steel will bend double as it is cast, and the casting does not need annealing, but only reheating to remove stresses set up during the cooling of the metal and reduce grain size.

Considerable controversy is being carried on at present on the relative merits of basic and acid electric steel for castings. For certain products it is claimed that the electric furnace has fulfilled its function in clearing up the accumulation of steel turnings alone, and that refining for sulphur and phosphorus is superfluous. In my opinion, although this may to some extent be true, it is not good policy to attempt to turn out anything but the best quality, as steel castings are the most nonuniform product of the steel-maker's art. Whatever may be the conditions now, I am convinced that only the best quality will command a profitable price after the war. 


\section{APPLICATION OF ELECTRIC FURNACE METHODS}

Electric furnaces have made a signal success of the manufacture of complex alloy steels of great purity. The reputation of my own type of furnace has been largely built up on its production of that almost sacred metal, high-speed steel.

It will readily be appreciated that two metals of such dissimilar densities as iron and tungsten, and with very slight chemical affinities, readily tend to separate out when in the molten condition. Some firms in Sheffield are so convinced of the uniformity of electric high-speed steel, however, that they have scrapped the crucible process.

The United States have over two hundred electric furnaces to-day; in Great Britain we have--.well, perhaps I might be giving valuable information to the enemy if I said how many. I think we were credited with 88 at the beginning of I9I 7 by an American journal.

It is noteworthy that Germany increased her electric steel output from 90,000 tons in $1_{9} I_{4}$ to 130,000 tons in $19 I_{5}$ and 225,000 in 1916 .

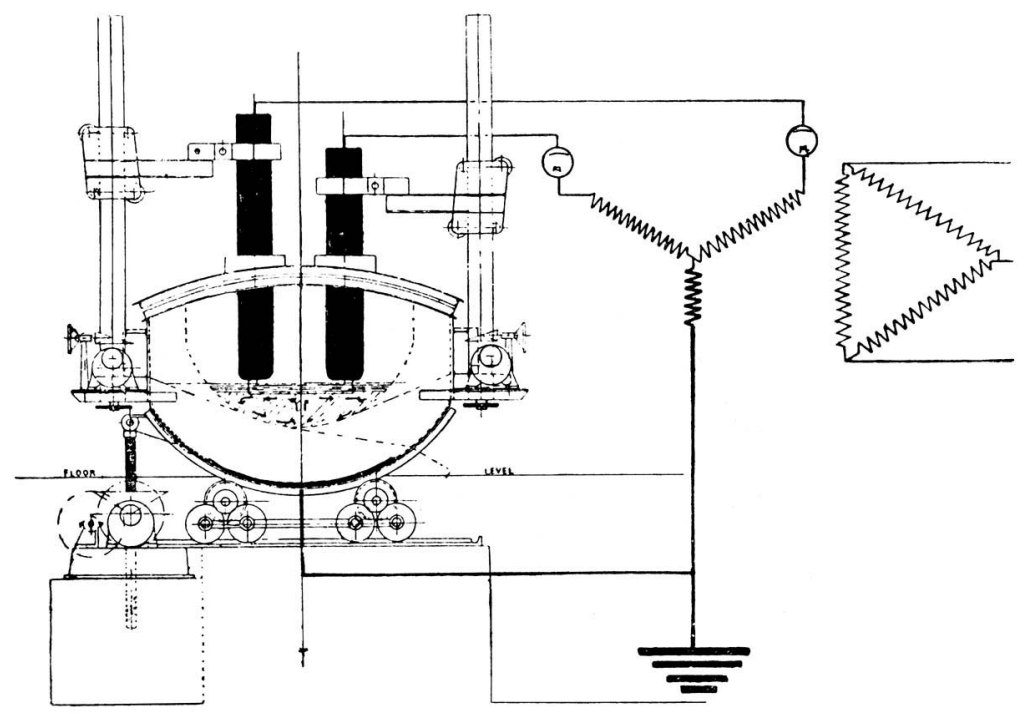

FIG. r.-Arrangement of I2-ton Furnace.

Electric furnaces of the contact arc type are generally realized as being the most convenient from the practical steel-maker's standpoint. The electrician would doubtless choose other types with higher power factor and steadier regulation. The three favoured types here are the Héroult, Electro-Metals, and Greaves-Etchells. The Héroult firm have adopted three suspended electrodes connected to a star or delta group of transformers, with the molten bath as an unconnected star-point. Electro-Metals connect each group of upper electrodes to one of two phases, and connect the hearth and molten bath as a common neutral.

In the Greaves-Etchells system we have made a distinct departure from standard methods of grouping and feeding the electrodes with electrical energy. Our system will be better understood by reference to the diagram, Fig. $x$.

A section of the furnace is shown on the left-hand side of the diagram with two block-shaded electrodes attached. These electrodes are each 
shown connected to separate terminals of the two transformer secondary windings on the right-hand side of the diagram. The other terminals of each of these transformer windings unite in a star point, together with one terminal of a third transformer secondary winding which is shown in rather heavier line. It will be noted that the outer terminal of this third winding is connected to the furnace bottom and to earth respectively. These three transformer windings, shown diagrammatically in a $Y$ form, are grouped in what is known as star arrangement. The star arrangement as it is generally known to electrical engineers must have equal resistances placed in the path of the currents from each of the three transformer outer poles, in order to give balanced load. In a furnace it is found impracticable to make the resistance of the furnace hearth equal to that of the arc maintained on each electrode, and therefore as regards the transformer connected to the hearth the symmetry of the star is unbalanced. The diagram on the far right-hand side of Fig. I shows the ordinary method of delta grouping for the primary windings, which are fed by three-phase high-tension supply currents and excite the secondary windings of the $\mathrm{Y}$ group. By a system of special transformation ratio, and special construction of the secondary winding of the transformer connected to the furnace hearth, we are able to convert the unsymmetrical and consequently unbalanced currents of the secondary system to give balanced load on the high-tension supply phases.

The advantages which accrue from this invention are as follows:-

I. The currents fed into the furnace by the upper electrodes, after traversing the arcs, must return to their respective transformers by passing through the hearth of the furnace because this offers the path: of least resistance. When the furnace is at working heat, the hearth has a definite uniform resistance, which is permanently in the path of the currents from the electrodes. Consequently if these currents increase unduly by reason of short circuit through the electrodes touching the metal in the furnace, the electrical resistance of the hearth acts as a limiting check to such short circuit.

2. By reason of the particular arrangement of transformer secondary windings, any current traversing the path from one electrode to another, or through the furnace hearth, must pass through two transformer secondary windings in series. Since these secondary windings are each excited by primary windings of different phase relationship the secondary current is in phase with neither. Being out of phase with both, the power factor of that particular secondary circuit is materially lowered, so that: any excess of current due to a short circuit on the electrode is again checked and limited by the increasing reduction of the power factor.

Providing the currents are normal, the lagging power factor of one side of the system is balanced by the leading power factor of the other, so that the overall power factor is very good The overall power factor is only lowered at a moment of short circuit.

The above two methods of limiting short circuit are invaluable, because other well known and largely used types of furnace have the transformer windings and electrodes grouped in such a manner that a short-circuit current has a clear run through, and the only check on it which can be imposed is by the introduction of heavy reactances in the circuit.

This results in the detrimental lowering of the overall power factor.

There is an advantage gained by generating heat in the lining of the 


\section{APPLICATION OF ELECTRIC FURNACE METHODS}

furnace, in that it effectively does away with the possibility of the steel being chilled on the furnace bottom and lumps of cold alloys which have been added remaining undissolved. A circulation of metal from bottom to top is promoted, which cannot take place in any other type of furnace, in all of which heat is applied at the top only.

In company with the Electro-Metals design, we share the advantage of working with independent arcs, which, of course, renders each electrode independently regulatable. In fact, regulating is so easy that it is entrusted constantly to the aspiring type of youth shown on the screen.

Electrical Conditions.-The electric furnace, simple and crude as it appears, offers quite a number of interesting problems to the electrician.

There was a time when the silver tongue of quite an otherwise highly respectable furnace salesman could convince electric power companies that an electric furnace would take all their surplus load when politely asked to do so, shut down obediently when requested, and in addition to giving unity or a leading power factor, would regulate like a lighting load. Well, of course, every one knows better now, but in case things are painted too black through an opposite extreme of thought, I may be excused drawing attention to several good and bad features.

Regulation is uneven and automatic regulators, although attending to their work better than the human element, cannot prevent lumps of steel scrap falling against an electrode and short-circuiting, or alternatively dropping suddenly away and breaking the arc. However, things are improving! I have just come away from starting a furnace which was set with instantaneous trips on a 6,600-volt system. One switch, set at roo per cent. overload, only came out once during the complete heat, and the other in series with it, and set at 50 per cent. overload, came out several times. No. 2 was made quite workable with the addition of a time-limit fuse.

Unreasonable importance had been attached to power factor in the past. Furnaces are now available which will give 85 per cent. to 90 per cent. power factor during the melting period, and even up to 93 per cent. during the refining perind; but it should be borne in mind that increased reactance, and consequently lower power factor, is often more necessary for creating the best conditions for the supply network.

Regulation, phase balance and wave distortion have not received the attention which they deserve. The most popular types of regulator do not work as sensitively as they might, and so cause hunting of the electrodes ; but as quite a number of new devices are in the air, early improvement in this respect may be looked for.

The oscillograph shows some interesting results in regard to wave distortion. I am fortunate this evening in being able to show you a few selected specimens of wave-form taken on different types of furnaces operated in Sheffield, which has a II,200-volt three-phase 50-period supply system.

The following curves were photographed with a Duddell oscillograph. Nearly all furnace installations are fitted with current transformers on the incoming high-tension phases, in order to operate the protective gear. In every case from which the following curves were taken, the secondary of these current transformers was normally carrying from 5 to ro amperes, so that it was easily arranged to shunt one-tenth of an ampere through the oscillograph.

No. 9 shows the curve obtained on a Greaves-Etchells 30-cwt. furnace 


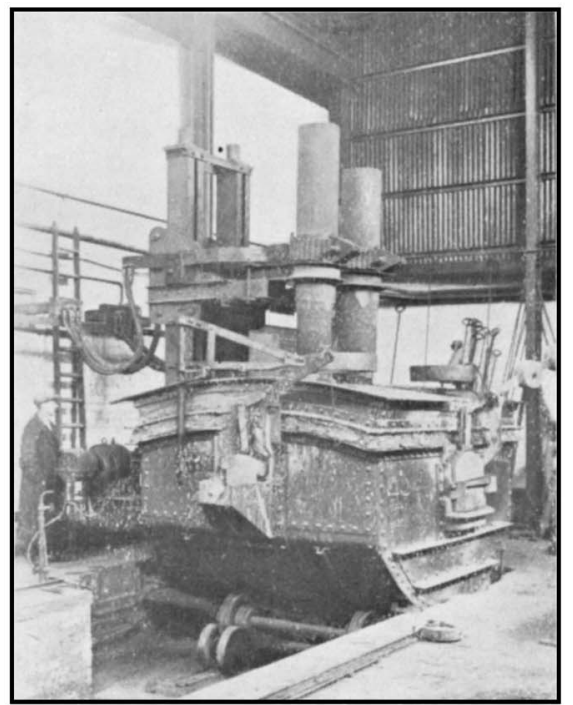

FIG. 2.-Early pattern of 3-ton GreavesEtchells Electric Furnace.

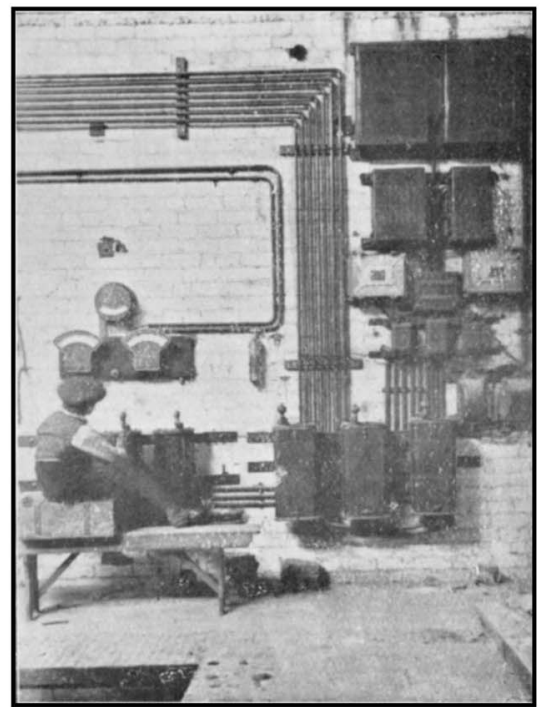

FIG. 3.-Boy regulating Greaves-Etchells Electric Furnace of 2-tons capacity. 


$$
\begin{aligned}
& 18 . \&: \& . \$ \\
& \$ \$ \$ \\
& \$ . \$ . \$ \$ \$ .8
\end{aligned}
$$


of $520 \mathrm{kv}$.a. capacity with slowly fluctuating load due to frothing of the slag during the finishing stage.

No. Io is another form taken under same conditions as No. 9.

No. I I shows the voltage wave obtained when the furnaces in this particular feeder were shut off.

No. I 2 the wave obtained on the same $520 \mathrm{kv}$.a. furnace when starting a fresh charge of cold metal, the load varying from Izo to I5O of full load in maintaining the arc in lumpy cold scrap.

No. 13 is another form taken under the same conditions as No. I2.

No. $2 \mathrm{I}$ shows a wave form obtained from the current transformer of a 3,000 kv.a., Io-ton capacity, four electrode type furnace on the Elektrometalls system. Note the increased distortion of the wave form and the peculiar ripples in the wave. This wave was taken during the steady or refining period.

No. 35 was taken on a 6 -ton Héroult furnace of $1,800 \mathrm{kv}$.a. capacity while the load was fluctuating badly during the period of melting cold metal.

No. 35 was taken under the same conditions as No. 35 .

No. 37 was taken about the same time as Nos. 35 and 36 .

No. 38 is another wave taken along with Nos. 35,36 , and 37 .

The following examples of low-tension wave form are interesting, although they do not rank in importance with the conditions obtaining on the high-tension side.

These wave forms were taken off the secondary side of the busbar current transformers encircling the low-tension loads to the electrodes.

No. $\mathrm{I} 8$ is the wave form obtained from a fully loaded electrode bus on the $520 \mathrm{kv} . \mathrm{a}$. Greaves-Etchells furnace, carrying 3,500 amperes.

No. 27 is taken from the 10 -ton Electro-Metals electrode bus carrying approximately 8,000 amperes.

No. $4^{\circ}$ is taken from the 6-ton Héroult furnace busbar carrying approximately 18,000 amperes.

All the above three curves were obtained under steady running conditions, while the bath was molten and covered with a frothy finishing slag.

\section{Conclusions.}

It is impossible for me at the present stage to comment fully on the results obtained. In the case of No. 27 there is definite indication of a prolonged period of inertia while the current changes polarity, and this must be reflected to some extent on the primary system.

It may be contended that the iron of the current transformers has some influence on the wave form, and this is very true. Recent experiments made directly from the high-tension feeder without the use of transformers definitely show a fifth harmonic component, and the effect of the current transformer iron is to soften the distortion of the wave.

The Héroult method of transformer grouping is particularly susceptible to the setting up of circulating currents, and this may to some extent account for the curious resultant waves produced in Nos. 35, 36, 37, and 38 .

I am indebted to Mr. S. Z. de Ferranti for the loan of his apparatus, and the kind assistance of some of his staff in successfully photographing these oscillograms.

These results only touch the fringe of what may be a big subject, but doubtless expert electricians can tell me whether or not I am right 


\section{APPLICATION OF ELEC'TRIC FURNACE METHODS}

in thinking that there is some ground for questioning the accuracy of induction-type watt-hour meters, as well as some indicating instruments.

The subject is important, inasmuch as it affects other apparatus connected to the system, such as, say, rotary converters.

Recent experiments have demonstrated that very appreciable losses may occur in getting power from the transformers into the furnace, not, as many people seem to think, entirely through eddy-current losses set up in surrounding inductive circuits, but because of the skin resistance of the furnace leads, which are otherwise amply calculated.

Dealing with large currents such as I0,000 amperes at low voltages of 70 or 80 volts, these losses assume quite respectable proportions, and in large furnace installations very special precautions should be taken to minimize them.

Possible sources of electrode losses should always receive due consideration. Carbon electrodes made up from pitch coke, anthracite, petroleum coke, etc., are the most widely used, and are the most siitable for processes such as ore reduction, where the carbonaceous oxide given off consumes the electrodes. These electrodes are readily and cheaply made under experienced supervision.

Continuous-feeding electrodes provided with jointing nipples are now gradually becoming popular, but attention is necessary to the making of a good joint between one piece and another. Personally, I think the only satisfactory method of jointing amorphous carbons is to use a graphite nipple.

For steel-making purposes graphite electrodes are infinitely superior to amorphous carbon. The latter can be run at an average current density of 25 amperes per square inch, while graphite can be run at an average of roo amperes.

The extra cost of graphite is always off-set by the lower consumption and convenience in handling. Great interest is taken at present in devising sealing glands at the point where the electrodes penetrate the roof or walls of the furnace, and we have obtained some surprising economies with some of our mechanical devices for this purpose. The retention of gases in the furnace saves the wearing of the roof, possibly by the particles of solid matter held in suspension reflecting the heat, instead of the roof. There is ample scope for invention in designing electrode holders with a minimum of contact resistance. Some designers overcome mechanical trouble by water-cooling, which involves a rigid holder, but I think the correct aim should be to avoid generating heat at this point. To this end I use an air-cooled flexible contact-belt.

The mechanical design of furnaces is more or less a matter of mechanical engineering skill, and is showing signs of settling down to uniform welldefined methods. Refractory materials are the metallurgist's chief difficulty, basic-lined furnaces still being tied down to using silica-brick roof. Trials have been made, and are likely to succeed in future, in the use of fused oxide-such as dolomite, magnesia, alumina-in brickmaking. As these have to be fused in the electric furnace, the industry needs undertaking on a grand scale to make it commercially attractive. 